Available online at GSC Online Press Directory

GSC Biological and Pharmaceutical Sciences

e-ISSN: 2581-3250, CODEN (USA): GBPSC2

Journal homepage: https://www.gsconlinepress.com/journals/gscbps

(RESEARCH ARTICLE)

\title{
Quality assessment and antibacterial properties of a commercial clove sample and copper sulphate as ingredients of an herbal mouth wash
}

\author{
Odumosu Patricia $\mathrm{O}^{1, *}$, Okwori Victoria $\mathrm{A}^{2}$ and Chris-Otubor Grace $\mathrm{O}^{3}$ \\ ${ }^{1}$ Department of Pharmaceutical \& Medicinal Chemistry Department, Faculty of Pharmaceutical Sciences, University of \\ Jos, P.M.B. 2084, Jos. Nigeria. \\ ${ }^{2}$ Department of Pharmacognosy and Traditional Medicine, Faculty of Pharmaceutical Sciences, University of Jos, P.M.B. \\ 2084, Jos. Nigeria. \\ ${ }^{3}$ Department of Pharmaceutical Microbiology \& Biotechnology, Faculty of Pharmaceutical Sciences, University of P.M.B. \\ 2084, Jos. Nigeria.
}

Publication history: Received on 17 September 2019; revised on 01 October 2019; accepted on 03 October 2019

Article DOI: https://doi.org/10.30574/gscbps.2019.9.1.0178

\begin{abstract}
Clove buds obtained from flower buds of (Syzygium aromaticum (L.) Merril et L. M. Perry (Eugenia caryophyllus C. Spreng. Bull et Harr) have been used in traditional medicine for a variety of ailments, as food spice and in aromatherapy. Some of the pharmacological properties have been reported as anti-bacterial, anti-inflammatory and antioxidant. The main constituent of clove is eugenol which has been reported and confirmed to have antibacterial action. The oil from the commercial clove sample was extracted using a Clevenger apparatus and assessed by gas chromatography for the content of eugenol in comparison to a standard clove oil. In addition, the TLC fingerprint, physicochemical and antibacterial properties were determined by standard methods to authenticate and establish the quality of the clove prior to use in the herbal mouthwash formulation. The sample clove oil exhibited minimum inhibitory concentrations (MIC) values of $<0.02-0.312 \mathrm{mg} / \mathrm{ml}$ and minimum bactericidal concentrations (MBC) of $0.156-0.312 \mathrm{mg} / \mathrm{ml}$ against selected gram positive and negative organisms. MIC and MBC values for Copper sulphate were in the range of $<0.02-0.156$ and $0.156-0.312 \mathrm{mg} / \mathrm{ml}$ respectively. The sample clove oil with $15 \%$ yield was determined to have $71.7 \%$ purity in comparison to the standard clove oil. The evaluation of the clove buds, oil and copper sulphate showed that it conformed to specifications and has potential for use in the mouthwash formulation.
\end{abstract}

Keywords: Clove buds; Copper sulphate; Herbal mouthwash; Chromatography; Antibacterial; Physicochemical evaluation

\section{Introduction}

Clove is the dried flower buds of Syzygium aromaticum (L.) Merrill \& Perry. Family Myrtaceae. The Synonyms includes: Caryophyllus aromaticus L. Eugenia aromatica (L.) Baill. Eugenia caryophyllata Thunb. and Eugenia caryophyllus (Spreng.) Bullock \& S. G. Harrison. It is indigenous to the Molucca or Clove Islands and cultivated in Zanzibar, Pemba, Madagascar, Indonesia, Brazil, Sri-Lanka and Tanzania [1]. Cloves are used in traditional medicine, aromatherapy and as food spice. The properties of pharmacological importance include antibacterial, antifungal; antiinflammatory, insecticidal and antioxidant which have been proven to be active because of high content of eugenol [2]. Other constituents such as the flavones, kaempferol and myricetin have demonstrated potent growth-inhibitory activity against the periodontal pathogens Porphyromonas gingivalis and Prevotella intermedia [2]. The safety and efficacy of medicinal plant materials and finished herbal medicinal products are a major source of concern for the

\footnotetext{
${ }^{*}$ Corresponding author

E-mail address: podumosu@unijos.edu.ng
} 
public, health authorities and pharmaceutical industries, especially with the increasing use of herbal medicines and the notion that natural is safe [3].

The herbal formulation containing dried flower buds of clove and copper sulphate as main ingredients is an indigenous formulation used for ethnomedicinal treatment of black tongue and other mouth infections in Nigeria [4]. The need for scientific validation of the medicinal potential of the formulation stimulated the interest in the study. The evaluation of the oil extracted from the commercial sample of clove buds by gas chromatography was to assess the quality compared to standard clove oil in order to determine its suitability for use in an herbal mouthwash. TLC profile for clove was determined as a quality control tool for subsequent analysis of the herbal mouth wash. Physicochemical evaluation and antibacterial studies were also conducted to obtain other quality parameters and to determine the inhibitory properties against selected bacteria.

\section{Material and methods}

\subsection{Collection of material}

Clove buds were bought in a local market in Katako, Jos Plateau State, Nigeria and foreign matter removed from the sample. This was placed in an airtight container until further use.

\subsection{Chromatography}

\subsubsection{Thin layer chromatographic conditions}

All solvents used were of analytical grade (Loba Chemie - India) and normal phase thin layer plates were silica gel 60 $\mathrm{F}_{254}$ (TLC-MS grade $5 \times 7.5 \mathrm{~cm}$, Merck, Germany). $0.5 \mathrm{~g}$ of clove buds was weighed accurately and transferred into a mortar and crushed to which $5 \mathrm{ml}$ of methanol was then added. The mixture was then transferred into a test tube and sonicated for about 10 mins using a water bath. The standard clove oil was diluted in methanol (1:5) and $2 \mu$ lof both samples were spotted on the thin layer plate and developed to $7 \mathrm{~cm}$ using two mobile phases which consisted of the solvents in the following ratios; Toluene $(100 \%)$ and Toluene: Ethyl acetate (95:5). The plates were visualized at UV $254 \mathrm{~nm}$ and in white light after spraying with anisaldehyde reagent.

\subsubsection{Oil extraction}

The dry clove buds were sorted and pulverized to powder using a glass mortar. The hydro distillation method utilizing the Clevenger apparatus (250 ml) was used to obtain the oil [5].

\subsubsection{Gas chromatographic conditions}

Gas chromatograph: Agilent Technologies 7890 Model

MS model 5975 Agilent Technologies

Injector model: $7683 \mathrm{~B}$

Column type: HP $5 \mathrm{~ms}(30 \mathrm{~m} \times 0.320 \mathrm{~mm} \times 0.25 \mu \mathrm{m})$

Amount injected: $1 \mu \mathrm{L}$ in $1 \mathrm{~mL}$ hexane

Temperature programming: $80^{\circ} \mathrm{C}$ (held for 2 minutes) and increased by $10^{\circ} \mathrm{C} / \mathrm{min}$ to the final temperature of $240{ }^{\circ} \mathrm{C}$ (held for 6 minutes).

\subsection{Physicochemical evaluation}

Microscopy, refractive index and ash value assays were conducted in accordance with British pharmacopoeial standards [5].

\subsection{Antibacterial activity determination}

\subsubsection{Macrodilution method}

[BSAC Susceptibility testing method 2010 (British Society for Antimicrobial Susceptibility) http://bsac.org.uk Last accessed 01/06/2010.]

Copper sulphate powder (BDH) at $100 \mathrm{mg} / \mathrm{ml}$ and clove oil (Sigma Aldrich) at $50 \mathrm{mg} / \mathrm{ml}$ were prepared using sterile distilled water and dimethyl sulfoxide (Sigma Aldrich) respectively. The double dilution method was employed for the 
antimicrobial susceptibility determination where double strength nutrient broth was prepared in a $5 \mathrm{ml}$ test tube and used to prepare single strength medium in subsequent tubes but the last $5 \mathrm{ml}$ quantity from the last tube was discarded.

Each freshly prepared bacterial isolate was diluted to 0.5 McFarland's standard and from the dilutions of each microorganism, $0.1 \mathrm{ml}$ was added to each tube to give final tube concentrations of $10 \mathrm{mg} / \mathrm{ml}$ to $0.02 \mathrm{mg} / \mathrm{ml}$. The tubes were then incubated at $35{ }^{\circ} \mathrm{C}$ for 24 hours and observed for the presence or absence of growth. The lowest concentration without visible growth was noted to be the minimum inhibitory concentration (MIC). For the minimum bactericidal concentration (MBC), all the tubes that had no growth were streaked on Muller Hinton agar and incubated at $35^{\circ} \mathrm{C}$ for 24 hours and compared to a growth control plate.

\section{Results and discussion}

\subsection{Chromatography}

The thin layer chromatograms spotted with clove standard oil and the methanol extract of clove sample showed one tailing spot in the system developed with toluene however, the plate developed with toluene: ethyl acetate (95:5) showed a better separation for the clove sample when visualized with anisaldehye reagent (Figs. 1a-1d).

The European Pharmacopoeia (EP 5.0) method for TLC profile of reference clove oil reports that using the normal phase silica gel and toluene, the chromatogram should show a quenching zone corresponding to eugenol and a weak quenching zone (acetyl eugenol) just below it. [https://www.academia.edu/22668992/European_pharmacopoeia_5.0. Accessed 30/09/2019]. On spraying with anisaldehyde solution and heating at $100-105{ }^{\circ} \mathrm{C}$ for 5 to $10 \mathrm{~min}$, the chromatogram when viewed in white light, is expected to show three quenching zones corresponding to eugenol (brownish-violet color), acetyl eugenol (faint-violet blue) and a reddish-violet zone corresponding to ß-caryophyllene. In comparison to two main peaks seen in standard clove oil the test sample expectedly showed a few more peaks. Thin layer chromatography has the advantage that samples spotted on the thin layer plates remain on them even when no separation takes place.
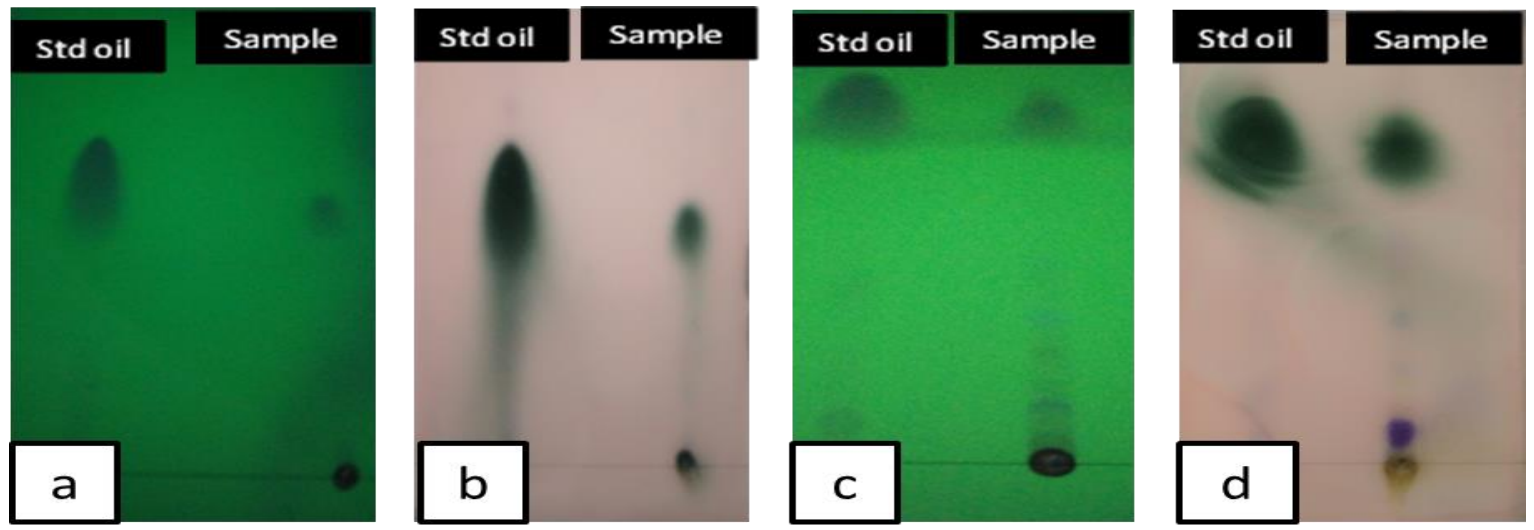

Figure 1 a) Silica gel $60 \mathrm{~F}_{254}$ TLC-MS grade plates spotted with standard clove oil and sample developed with toluene and viewed under UV $254 \mathrm{~nm}$. b) Duplicate plate viewed in white light after spraying with anisaldehyde. c) Plate developed with toluene: ethyl acetate (95:5) and viewed under UV $254 \mathrm{~nm}$. d) Duplicate plate viewed in white light after spraying with anisaldehyde.

The major constituents of clove buds have been reported to be eugenol, acetyl eugenol and caryophyllene. In a Bangladeshi study, about 31 compounds in clove oil were characterized through gas chromatography-mass spectrophotometer with main constituents being eugenol $49.7 \%$, caryophyllene $18.9 \%$ benzene,1-ethyl-3-nitro $11.1 \%$ and benzoic acid,3-(1-methylethyl) 8.9\% [6]. The extraction of the oil from $4 \mathrm{~g}$ clove sample over a period of 2 hours yielded a mean volume of $0.6 \mathrm{ml}(15 \%)$ which is comparable to literature values.

From literature, the phytochemical constituent of cloves consists of volatile oil $14-21 \%$ and tannins $10-13 \%$, various triterpene acids and esters and glycosides. The content of phenols in the oil is estimated to be between $85-90 \%$ consisting of eugenol with about 3\% acetyl eugenol, sesquiterpenes ( $\alpha$ - and $\beta$-caryophyllenes) and small quantities of esters, ketones and alcohol [1]. Factors such as temperature, rainfall, altitude, geographical location have been known 
to affect the oil yield. It has been reported that the yield of essential oils appears to be enhanced at higher temperatures [7].

Also, the drying process can play an important role in the yield as it is believed that the oil glands or cellular materials rupture and release the oil. So, in order to maximize the yield, there may need to be a controlled drying step where the temperature and humidity are kept below $50 \%$ in the processing of the oil [8].

The GC profile of the sample oil in comparison to the standard oil also showed similar peaks and good correlation with a $71.7 \%$ purity (Table 1). The compound identification of eugenol was made by comparing mass peaks with NIST library data and with those reported in literature. The relative percentages were calculated from GC peak areas and the results showed that the oils are a complex mixture as reported by other investigators, but eugenol was the main component with $51.11 \%$ in comparison to $71.24 \%$ for the standard oil (Table 1). The B.P gas chromatographic method estimates a 75 - 88\% limit for eugenol in pharmaceutical grade clove oil known in commerce as 'opt' due to the low level of phenolic content [1]. The level of alpha-caryophyllene was calculated to be $1.54 \%$ for the standard as against $12.15 \%$ for the sample which may explain why only one major spot was observed in the thin layer chromatograms for the standard (Fig.1)

Table 1 GC data for clove standard oil and sample oil

\begin{tabular}{llllll}
\hline Sample & $\begin{array}{l}\text { Retention } \\
\text { time (min) }\end{array}$ & $\begin{array}{l}\text { Peak area } \\
\text { (\%) } \\
\text { Eugenol }\end{array}$ & $\begin{array}{l}\text { Retention time } \\
\text { (min) }\end{array}$ & $\begin{array}{l}\text { Peak area (\%) } \\
\boldsymbol{\alpha} \text {-caryophyllene }\end{array}$ & $\begin{array}{l}\text { Minimum } \\
\text { quality/similarity } \\
\text { index \% }\end{array}$ \\
\hline Clove standard & $9.899-12.365$ & 71.24 & $12.514-12.537$ & 1.54 & $>90$ \\
Clove sample & $9.882-11.450$ & 51.11 & $11.518-11.793$ & 12.15 & $>90$ \\
\hline
\end{tabular}
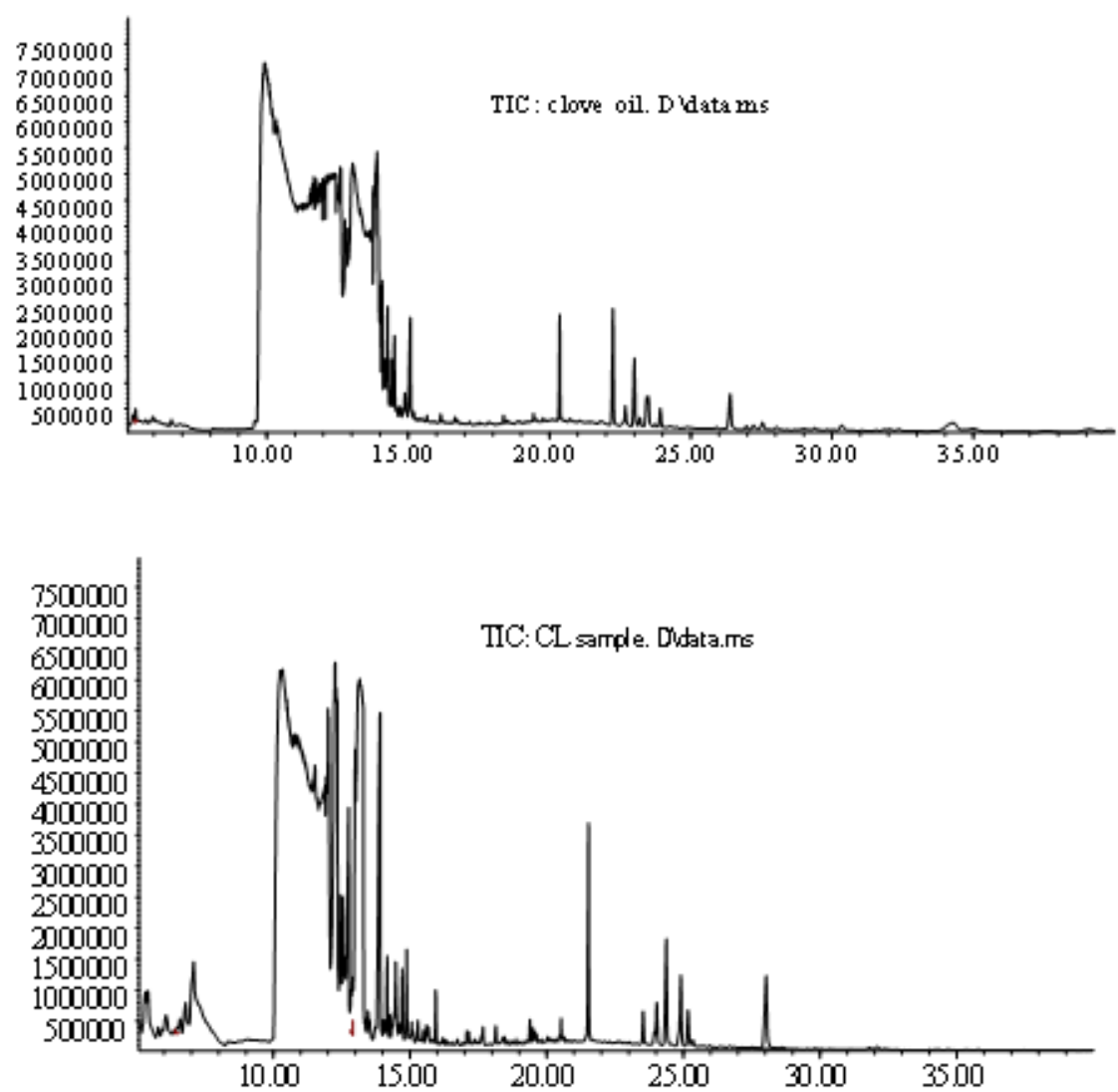

Figure 2 a) GC profiles of clove standard oil sample showing abundance against time (min). b) GC profile of clove oil extracted from commercial sample of cloves. 


\subsection{Physicochemical evaluation}

The refractive index of the oil was in the range of $1.516-1.526$ compared to the B.P value of 1.528-1.537 [5]. The value falls in line with the percentage purity of 71.7 indicating the need for tighter control of the drying and extraction processes. Ash values (1.1\%) determined for the clove powder met the B.P specifications of not more than $7 \%$ and this represents the measure of specific inorganic components present within a substance. The presence of these minerals affects the quality with regards to taste, appearance, texture and stability. The clove powder was examined microscopically, and it was found to possess epidermal cells, phloem fibers, pollen grains, parenchyma, sclereid cells and fragment of the hypanthium showing a portion of the oil gland. (Figs. 3a-3g). This results also meet B.P specifications and shows that the clove material is of good quality as a starting material for the herbal mouthwash.
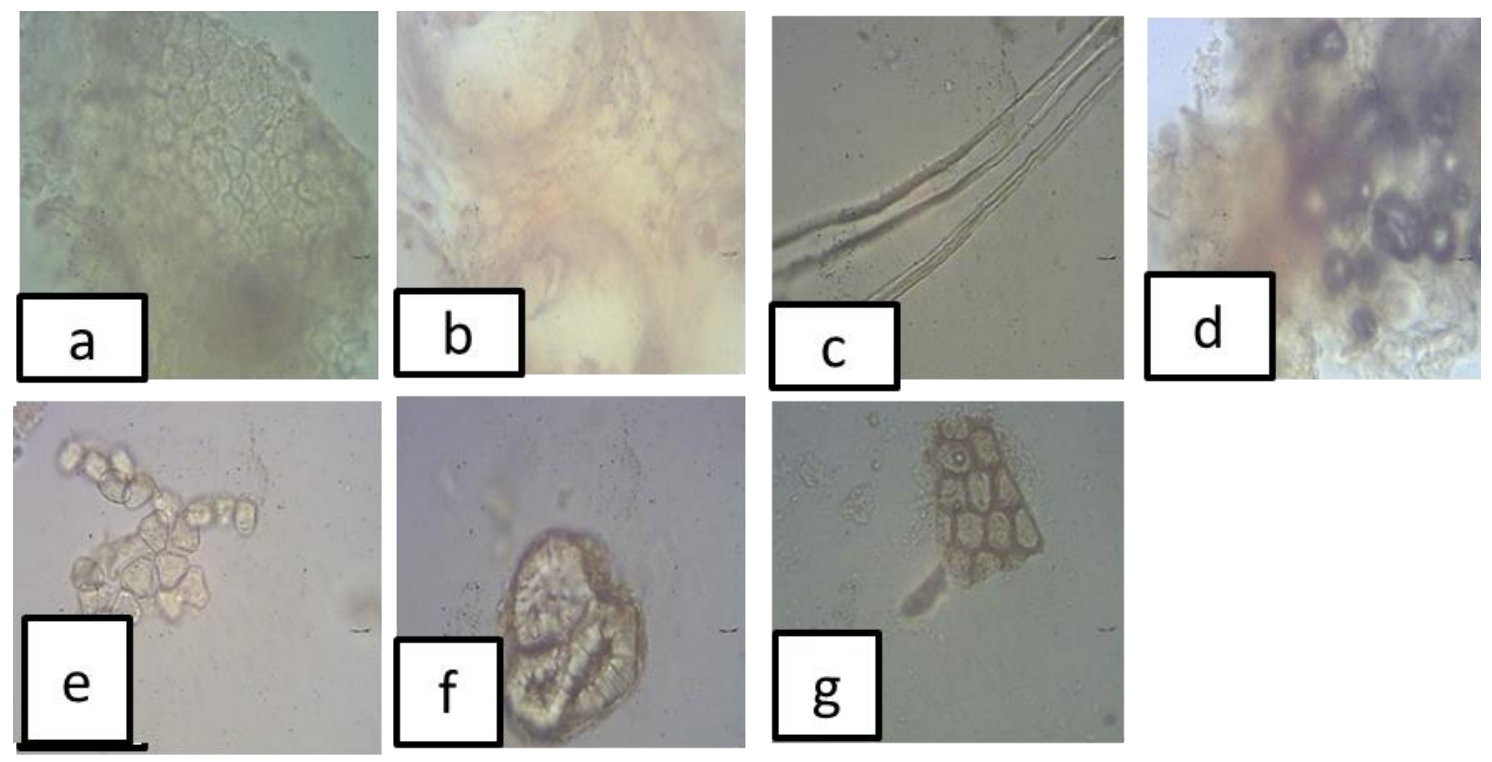

Figure 3 Microscopy of clove powder showing; a). Epidermal cell b). Fragment of hypanthium showing portions of oil gland c). Phloem fibre x40 d). Epidermal cell and stoma of hypanthium e). Pollen grains f). Sclereid g). Parenchyma of hypanthium

Unlike conventional pharmaceutical products, which are usually produced from synthetic materials by means of reproducible manufacturing techniques and procedures, herbal medicines are prepared from materials of herbal origin, which are often obtained from different geographical and/or commercial sources. As a result, it may not always be possible to ascertain the conditions to which they may have been subjected or the composition and properties. Furthermore, the procedures and techniques used in the manufacture and quality control of herbal medicines are often very different from those employed for conventional pharmaceutical products. Sometimes, there are reports of contamination with toxic medicinal plants and/or plant parts and due to the small quantity of defined active ingredients, the production and primary processing has a direct influence on the quality of herbal medicines. For this reason, application of GMPs in the manufacture of herbal medicines is an essential tool to assure their quality [3].

\subsection{Antibacterial activity}

The inhibitory activities of the clove sample oil and copper sulphate are shown in Tables $2-3$. The results suggest that the final broth dilution concentrations which ranged between $10 \mathrm{mg} / \mathrm{ml}$ and $0.02 \mathrm{mg} / \mathrm{ml}$ in the tubes possess inhibitory properties though the degree of susceptibility varied among the bacterial species. The action was against both gram positive and gram-negative organisms implying that the components have good spectrum of activity. However, the final concentrations in the mouthwash would need to be titrated in order to determine synergy or additive effects as reported in another study [9].The MIC which is defined as the lowest concentration of an antimicrobial ingredient or agent that prevents the visible growth of bacteria (bacteriostatic) is used to evaluate the antimicrobial efficacy of various compounds by measuring the effect of decreasing concentrations of antibiotic/antiseptic over a defined period in terms of inhibition of microbial population growth.

These evaluations have been reported to be of great value during the R\&D phase of a product to determine appropriate concentrations required in the final product, as the concentration of drug required to produce the effect is normally much less than the concentration found in the finished dosage form. [https://www.qlaboratories.com 
/minimum-inhibitory-mic-and-minimum-bactericidalconcentration-mbc-evaluations-as-rd-tools/Last accessed 12/09/2019].

According to Chitwood the tube dilution method has better accuracy compared to the disc method when determining antimicrobial susceptibility in clinical situations [10]. The MBC values determined for sample clove oil was between $0.156-2.5 \mathrm{mg} / \mathrm{ml}$ while the values for copper sulphate ranged between $0.156-0.312 \mathrm{mg} / \mathrm{ml}$ [Tables 2 and 3]. The MBC is defined as the lowest concentration of an antibacterial agent required to kill a bacterium over a fixed, somewhat extended period, such as 18 hours or 24 hours, under a specific set of conditions. These values were determined by streaking fresh plates from the MIC tubes that had no growth. The MBC is identified by determining the lowest concentration of antibacterial agent that reduces the viability of the initial bacterial inoculum by a predetermined reduction such as $\geq 99.9 \%$.

Table 2 Minimum Inhibitory Concentration (MIC) and Minimum Bactericidal Concentration (MBC) (in mg/ml) of clove oil against the various organisms

\begin{tabular}{lll}
\hline ORGANISMS & $\begin{array}{l}\text { MIC } \\
\text { (av) }\end{array}$ & $\begin{array}{l}\text { MBC } \\
\text { (av) }\end{array}$ \\
\hline Bacillus sp. & 0.78 & 0.78 \\
Streptococcus sp. & 1.56 & 7.81 \\
Klebsiella sp. & 0.78 & 0.78 \\
Staphylococcus aureus & $<0.10$ & 1.17 \\
Pseudomonas aeruginosa & 0.78 & 0.78 \\
\hline
\end{tabular}

Table 3 Minimum Inhibitory Concentration (MIC) and Minimum Bactericidal Concentration (MBC) (in mg/ml) of Copper Sulphate against the various organisms

\begin{tabular}{lll}
\hline ORGANISMS & $\begin{array}{l}\text { MIC } \\
\text { (av) }\end{array}$ & $\begin{array}{l}\text { MBC } \\
\text { (av) }\end{array}$ \\
\hline Bacillus sp. & 0.49 & 0.88 \\
Streptococcus sp. & 0.78 & 1.56 \\
Klebsiella sp. & $<0.10$ & 0.78 \\
Staphylococcus aureus & 0.78 & 0.88 \\
Pseudomonas aeruginosa & 0.39 & 0.98 \\
\hline
\end{tabular}

*All determinations were conducted in triplicate

The MBC is believed to be complementary to the MIC in the sense that while the MIC test demonstrates the lowest level of antimicrobial agent that greatly inhibits growth, the MBC demonstrates the lowest level that results in microbial death. This in effect implies that if a MIC shows inhibition, sub-culturing the bacteria might still result in organism proliferation because the antimicrobial did not cause death. Antibacterial agents are usually regarded as bactericidal if the MBC is no more than four times the MIC and this has been reported to be a cost-effective tool to evaluate multiple antimicrobial agents for potency and to evaluate formulation problems where it is suspected that the active ingredient may be complexed by other ingredients [https://www.qlaboratories.com/minimum-inhibitorymic-and-minimum bactericidal-concentration-mbc-evaluations-as-rd-tools/ Last accessed 12/09/2019]. The MBC results (at approximately x 4 MIC) for sample clove oil against Streptococcus shows that it might possibly be bactericidal at the concentrations tested against the Streptococcus species (Table 2). On the other hand, copper sulphate MBC results show potential bactericidal effect against Pseudomonas spp. (Table 3). Further studies incorporating the other ingredients in the herbal mouthwash would provide a more comprehensive potential of the product. 


\section{Conclusion}

The quality assessments of the clove sample present the potential utility of the herbal material as an ingredient of the antibacterial mouthwash and the provision of additional antibacterial properties by copper sulphate. The eugenol content can be used as a marker for quality assurance of the herbal product.

\section{Compliance with ethical standards}

\section{Acknowledgments}

The assistance of Mr. Solomon Julius of the Pharmacognosy Department, University of Lagos, Nigeria and Godwin Victor, University of Jos, Nigeria is acknowledged.

\section{Disclosure of conflict of interest}

The authors declare no conflict of interest.

\section{References}

[1] Evans WC. (2008). Trease and Evans Pharmacognosy. 15th Edition. W.B. Saunders. 250-274.

[2] Cai L and Wu CD. (1996). Compounds from Syzygium aromaticum possessing growth inhibitory activity against oral pathogens. Journal of Natural Products, 59 (10), 987-990.

[3] World Health Guidelines on good manufacturing practices [GMP] for herbal medicines. (2007). 1-21. https://apps.who.int/medicinedocs/documents/s14215e/s14215e.pdf

[4] Hollist NO. (2004). A collection of traditional Yoruba oral and dental medicaments. Edited by Book Builders and Printed by Oluben Printers, Ibadan, Nigeria. 29.

[5] British Pharmacopoeia. (1993). Volume 1. Published by Stationery Office Books. Great Britain.

[6] Bhuiyan NI, Begum J, Nandi NC and Akter F. (2010). Constituents of the essential oil from leaves and buds of clove (Syzigium caryophyllatum (L.) Alston). African Journal of Plant Science, 4 (11), 451- 454.

[7] Canvin, DT. (2011). The effect of temperature on the oil content and fatty acid composition of the oils from several oil seed crops. Canadian Journal of Botany, 43(1), 63-69. DOI: 10.1139/b65-008

[8] Braga NP, Cremasol MA and Valle RCCR. (2005). The effects of fixed bed drying on the yield and composition of essential oil from long pepper (Piper hispidinervium c. dc) leaves. Brazilian Journal of Chemical Engineering, 22 (2), 257-262.

[9] Odumosu PO and Thomas K. (2015). Drug interaction studies of Ximenia americana and Pavetta crassipes methanol extract with standard antibiotics. Journal of Pharmacy \& Bioresources, 12 (2), 150-155.

[10] Chitwood LA. (1969). Tube dilution antimicrobial susceptibility testing: efficacy of a micro technique applicable to diagnostic laboratories. Applied Microbiology, 17 (5), 707-709.

\section{How to cite this article}

Odumosu PO, Okwori VA and Chris-Otubor GO. (2019). Quality assessment and antibacterial properties of a commercial clove sample and copper sulphate as ingredients of an herbal mouth wash. GSC Biological and Pharmaceutical Sciences, 9(1), 32-38. 